IZA DP No. 9878

Rising Work Complexity but Decreasing Returns Anna Katharina Pikos

Stephan L. Thomsen

April 2016 


\title{
Rising Work Complexity but Decreasing Returns
}

\author{
Anna Katharina Pikos \\ Leibniz Universität Hannover \\ Stephan L. Thomsen \\ NIW, Leibniz Universität Hannover, \\ ZEW and IZA
}

\section{Discussion Paper No. 9878 \\ April 2016}

\author{
IZA \\ P.O. Box 7240 \\ 53072 Bonn \\ Germany \\ Phone: +49-228-3894-0 \\ Fax: +49-228-3894-180 \\ E-mail: iza@iza.org
}

\begin{abstract}
Any opinions expressed here are those of the author(s) and not those of IZA. Research published in this series may include views on policy, but the institute itself takes no institutional policy positions. The IZA research network is committed to the IZA Guiding Principles of Research Integrity.

The Institute for the Study of Labor (IZA) in Bonn is a local and virtual international research center and a place of communication between science, politics and business. IZA is an independent nonprofit organization supported by Deutsche Post Foundation. The center is associated with the University of Bonn and offers a stimulating research environment through its international network, workshops and conferences, data service, project support, research visits and doctoral program. IZA engages in (i) original and internationally competitive research in all fields of labor economics, (ii) development of policy concepts, and (iii) dissemination of research results and concepts to the interested public.
\end{abstract}

IZA Discussion Papers often represent preliminary work and are circulated to encourage discussion. Citation of such a paper should account for its provisional character. A revised version may be available directly from the author. 
IZA Discussion Paper No. 9878

April 2016

\section{ABSTRACT}

\section{Rising Work Complexity but Decreasing Returns}

Work complexity can be an important factor contributing to the observed employment and wage developments. Using German data, we find that it increased substantially between 1986 and 2012. Work complexity was higher for high-educated employees in the past but differences have leveled out in 2012 due to a steeper increase in complexity among lower educated. Although complexity is associated with higher wages, expected returns have decreased substantially since 1986. Lower education was associated with higher returns to complexity but these decreased over time, too. Thus, the more complexity becomes "normal", the less it is important in determining the wage.

JEL Classification: J21, J24, J31

Keywords: task-based approach, work complexity, returns to work complexity

Corresponding author:

Stephan L. Thomsen

NIW Hannover

Königstr. 53

D-30175 Hannover

Germany

E-mail: thomsen@niw.de 


\section{Introduction}

The task-based approach has become very popular in explaining the polarization of the labor market: employment and wages of low-skilled and high-skilled jobs increased at the expense of middle-skilled jobs indicating that the effects of technological change may not be monotonous in skills. Autor, Levy, and Murnane (2003) argued that specific work activities were at the core of the substitution process. By aggregating work activities to task categories, they showed that computer technology substituted routine work and complemented nonroutine work. More importantly, routine work dominated in the middle of the skill distribution, whereas non-routine work was present both at the very bottom and the top. Similar patterns of labor development were observed for other countries (see Goos, Manning, and Salomons, 2014 for an overview).

Recently, Beaudry, Green, and Sand (2016) documented that the demand for cognitive tasks reversed after the year 2000, and Green and Sand (2015) showed that even in the US wage polarization occurred only in one or at best two decades. Hence, polarization may have been a temporary phenomenon that is not likely to continue into the far future (Autor, 2015). Even though technology can substitute many routine components of jobs, most jobs still require non-routine components like flexibility, judgment, and common sense. The fact that routine and non-routine components cannot be disentangled limits the substitution possibilities.

Put in a different perspective, work complexity may play an important role that should be considered more explicitly. The task-based approach - despite its plausible intuition and undisputable value in explaining employment and wage developments - may veil important interdependencies between different tasks within occupations. If work complexity (measured by the number of task categories) changed over time, this could be an important factor 
contributing to the observed employment and wage developments. We study the evolution of work complexity and its returns using comprehensive German task-based data for the years 1986 to 2012.

Work complexity has substantially risen. It was comparatively low in 1986: nearly $40 \%$ of the employees performed tasks of a single category, and only $10 \%$ carried out activities of three or more different task categories. In 2012, the picture is reversed. This implies that differences across task categories decreased substantially, and thus, single task categories are not characteristic anymore for occupations - at least in Germany. At the same time, returns to complexity have fallen since 1986 .

\section{Data}

To analyze changes of work complexity over time, we use comprehensive data that stem from four surveys on qualification and career carried out in 1985/86, 1991/92, 2006 and 2012. ${ }^{1}$ The surveys provide detailed information on activities performed during work and a wide range of socio-demographic (gender, age, whether people live together with a partner and whether they have children), qualification (level of attained school graduation and tenure) and company characteristics (company size and industry). Spitz-Oener (2008) and Black and Spitz-Oener (2010) used the same data for different time spans and constructed task measures to analyze the returns to computer use and the evolution of the gender wage gap.

We restrict our sample to 18- to 65-year-old Germans and exclude East German residents and self-employed. The size of the samples varies from nearly 16,000 in 1986 to 8,700 in 2012. The number of individual work activities recorded differs from 15 (2006) to 25 (1992).

\footnotetext{
${ }^{1}$ The SUFs were provided by Leibniz Institute for Social Sciences (GESIS), first two waves, and the Research Data Centre of the German Federal Institute for Vocational Training (Bundesinstitut für Berufsbildung, BIBB), last two waves.
} 
We aggregate work activities to five task categories following the task literature (e.g. Autor et al., 2003): 1) non-routine manual (repair, renovate, restore, nurse), 2) routine manual (operate, control machines), 3) routine cognitive (calculating, measuring, book-keeping), 4) non-routine interactive (negotiate, teach, entertain, and manage personnel) and 5) non-routine analytic (research, evaluation, planning, interpret rules) tasks. Table A.1 in the appendix gives an overview over the task measure construction for each year.

We measure complexity by the number of task categories performed by the individual and standardize the resulting measure for regression analysis. In order to control for the main individual task, we calculate task category intensities as the percentage of activities in a task category (number of performed/number of possible tasks) and define the category with highest percentage as the main task category. In case of ties (i.e. more than one category obtains the highest number), we chose the higher category in terms of abstraction, i.e. the more intellectually demanding category. As an alternative, we consider the category in which the individual carries out the highest number of activities (absolute) as main task. Again, if more than one category has the highest number, the "higher" category is defined as main.

\section{Development of Work Complexity}

Work complexity has substantially increased during the last decades (Figure 1). In 1986, close to $40 \%$ of the employees undertook tasks of a single category. One out of five persons was engaged in tasks of three different categories already. The distribution in 1992 is very similar to 1986 . In 2006, work complexity was already high and very common among the working population. Within 20 years from the beginning of our time horizon, the share of people performing four categories became larger than the share performing a single category (20\% and 15\%). Additionally, there were more people with three than two different task categories (30\% and 26\%) and about $10 \%$ undertook even all five. These figures remained 
similar in 2012. Hence, work complexity is no longer the exception but has become the rule of workplace reality.

Figure 1. Share of Employees Performing a Certain Number of Tasks (1986 to 2012)

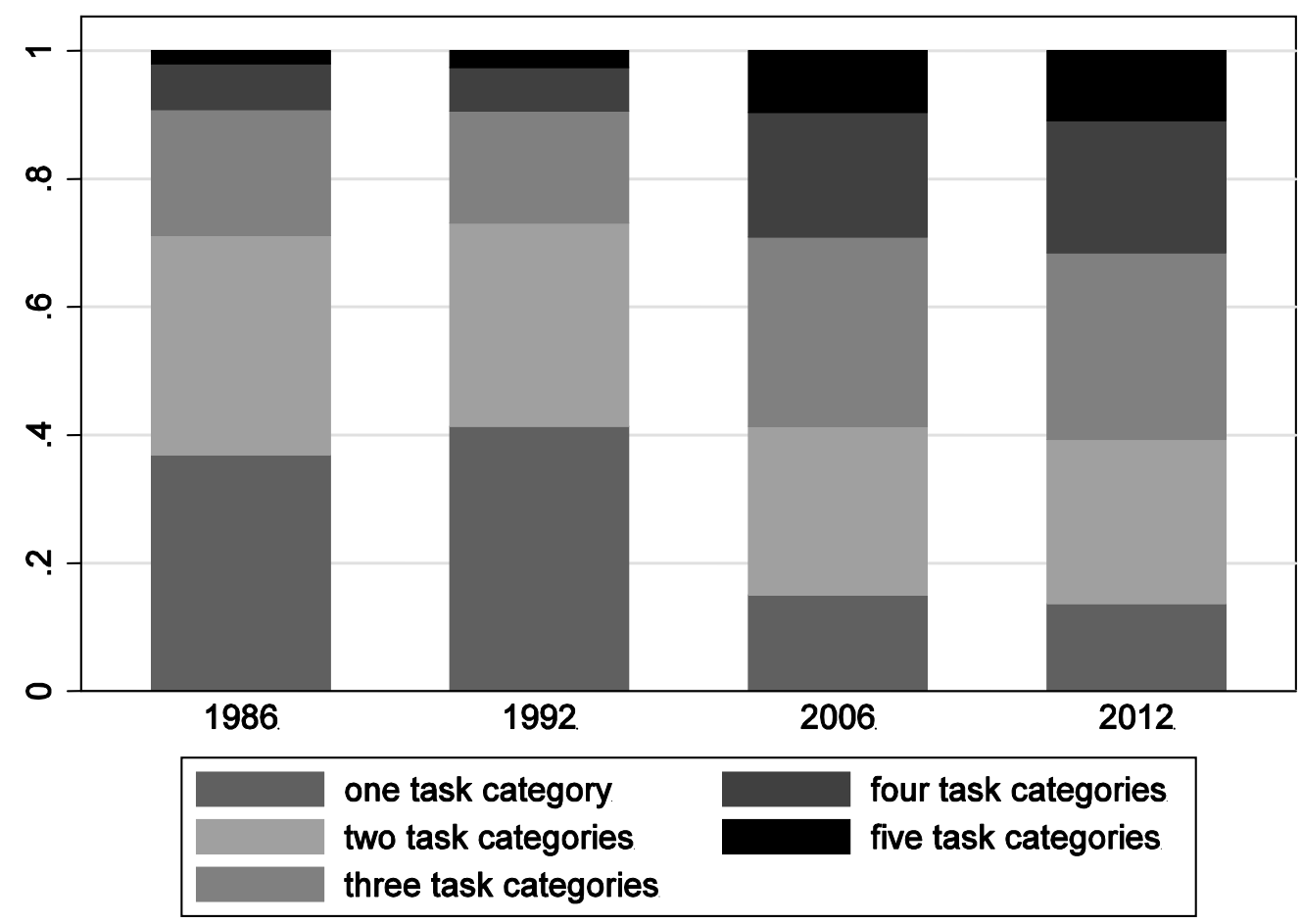

Data sources: IAB, BiBB, BAuA. Own calculations. See text for details.

When we look at the share of people performing the main task of their company's NACE sector (Statistical Classification of Economic Activities in the European Community, level 1, results not displayed), we find that task heterogeneity has risen even within sectors and less people perform the characteristic tasks. For instance, the share of "mainstream" task performers fell from $32 \%$ in 1986 to $28 \%$ in 2012. Due to the long time horizon we consider, the changes in the NACE structure of the German economy may influence this observation, i.e. weaker mainstream dominance could - to some extent - be driven by structural change in addition to task change.

Related to the literature on the skill-biased technological change hypothesis, we hypothesize that returns to complexity may not be homogeneous over the qualification 
distribution. We measure education by the highest school degree obtained in the tripartite school system in Germany (low: Hauptschule, medium: Realschule, high: Abitur) and find a heterogeneous pattern (Figure 2). Highly educated employees performed on average 2.5 task categories in 1986, whereas the low-educated carried out 1.8 . This is not very surprising as certain professions such as manager demand a higher complexity than for example an assembly line worker or a waiter. Work complexity started to take-off after the mid-1990s for all groups. Low educated experienced the steepest increase in work complexity and in 2006, any differences by education nearly disappeared.

Figure 2. Average complexity over years by education

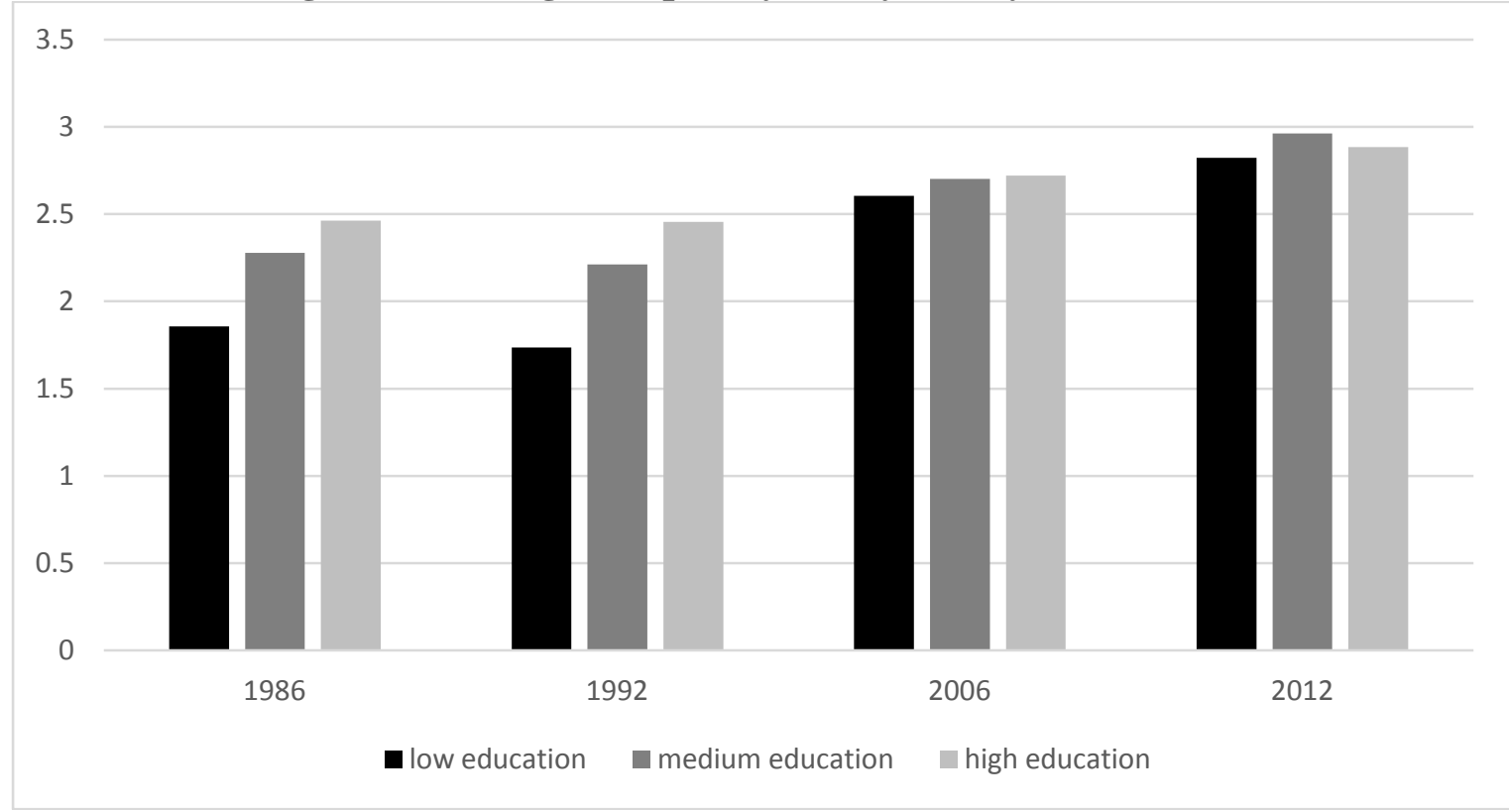

Data sources: IAB, BiBB, BAuA. Own calculations. See text for details.

These results indicate that both workplace heterogeneity and work complexity changed substantially over the last three decades - at least in Germany. Moreover, it affected the whole workforce independently of industry sector or qualification level.

\section{Estimation of the Returns to Work Complexity}

To quantify the individual returns to work complexity over time, we start by estimating the following earnings equations for the four survey waves by OLS: 


$$
\ln \left(\text { wage }_{i}\right)=\alpha_{0}+\beta_{1} \text { complexity }+\mathbf{S o c}^{\prime} \gamma_{1}+\mathbf{Q u a l}^{\prime} \gamma_{2}+\mathbf{C o m}^{\prime} \gamma_{3}+\varepsilon_{i}
$$

The dependent variable $\ln \left(\right.$ wage $\left._{i}\right)$ is $\log$ hourly wage that we calculate by dividing monthly gross income by the number of hours worked. We convert all values to 2012 prices using the consumer price index (CPI) from the Federal Statistical Office. After regressing log wages on complexity only, we specify a more comprehensive model. We control for the effects of other characteristics denoted by the matrices Soc (sociodemographic characteristics: gender, age, age squared, partner, children), Qual (qualification variables: dummy variables for low and high education, tenure, tenure squared) and Comp (company's size and industry) and estimate the coefficient vectors $\gamma_{1}, \gamma_{2}$ and $\gamma_{3} . \varepsilon_{i}$ is the error term. The coefficient of interest is $\beta_{1}$ denoting the wage change in response to a change of one standard deviation of work complexity. In a second step, we allow for year-specific complexity effects in by interacting year dummies $T$ with the complexity measure ( $T^{*}$ complexity):

$$
\begin{aligned}
\ln \left(\text { wage }_{i}\right)= & \alpha_{0}+\beta_{1} \text { complexity }+\beta_{2} T+\beta_{3} T * \text { complexity }+ \\
& \text { Soc' }^{\prime} \gamma_{1}+\mathbf{Q u a l}^{\prime} \gamma_{2}+\mathbf{C o m}^{\prime} \gamma_{3}+\varepsilon_{i} .
\end{aligned}
$$

The yearly complexity effects are the sum of the estimated coefficient for the corresponding interaction term and the complexity coefficient $\left(\beta_{1}+\beta_{3}\right)$.

As shown above (section 3), initially, job complexity was higher for high educated but due to steeper increases, differences had nearly disappeared by 2006 . The same is not necessarily true for wages: Considering that the returns to complexity decreased as it became more common to carry out more tasks, the relative complexity of a job for an individual compared with the coworkers may matter. To account for this, we interact education with complexity and control for sociodemographic characteristics (Soc: see above) and tenure (Ten: tenure, tenure squared):

$$
\ln \left(\text { wage }_{i}\right)=\alpha_{0}+\beta_{1} \text { complexity }+\beta_{2} E d u c+\beta_{3} E d u c * \text { complexity }+
$$




$$
\operatorname{Soc}^{\prime} \gamma_{1}+\operatorname{Ten}^{\prime} \gamma_{2}+\varepsilon_{i}
$$

Finally, we control for individual main task, first by considering a relative and second, an absolute measure to define a main task (see section 2):

$$
\begin{gathered}
\ln \left(\text { wage }_{i}\right)=\alpha_{0}+\beta_{1} \text { complexity }+\beta_{2} \text { Main }+ \\
\text { Soc }^{\prime} \gamma_{1}+\text { Qual' }^{\prime} \gamma_{2}+\varepsilon_{i} .
\end{gathered}
$$

\section{Returns to Work Complexity}

In this section, we provide a graphical overview of the returns to complexity. All estimated and calculated coefficients of interest, standard errors and adjusted $\mathrm{R}^{2}$ can be found in Table A.2 in the appendix. Figure 3 displays that higher work complexity was compensated for by higher wages over the whole period but the returns to work complexity decreased. In 1986, an increase in work complexity by one standard deviation was associated with an increase in hourly wage by $12 \%$. Work complexity on its own explained $5 \%$ of the variation.

Controlling for sociodemographic, qualification and company characteristics reduces the effect to $8 \%$. The coefficient decreased to $10 \%(6 \%)$ in 1999 but work complexity explained $6.7 \%$ of the variation. Since then, its explanatory power reduced to virtually zero $(0.4 \%)$ in 2012. The coefficient estimates are also lower with $6.2 \%$ in 2006 and $3.2 \%$ in $2012 .^{2}$

\footnotetext{
${ }^{2}$ When we control for a set of sociodemographic variables (gender, age, age squared, cohabitation/marriage, children, level of education), job and company characteristics (tenure, tenure squared, firm size, nine NACE sectors), the picture of the estimated coefficients looks similar (see Table A.2).
} 
Figure 3. Returns to Work Complexity (1986 to 2012, OLS Estimates)

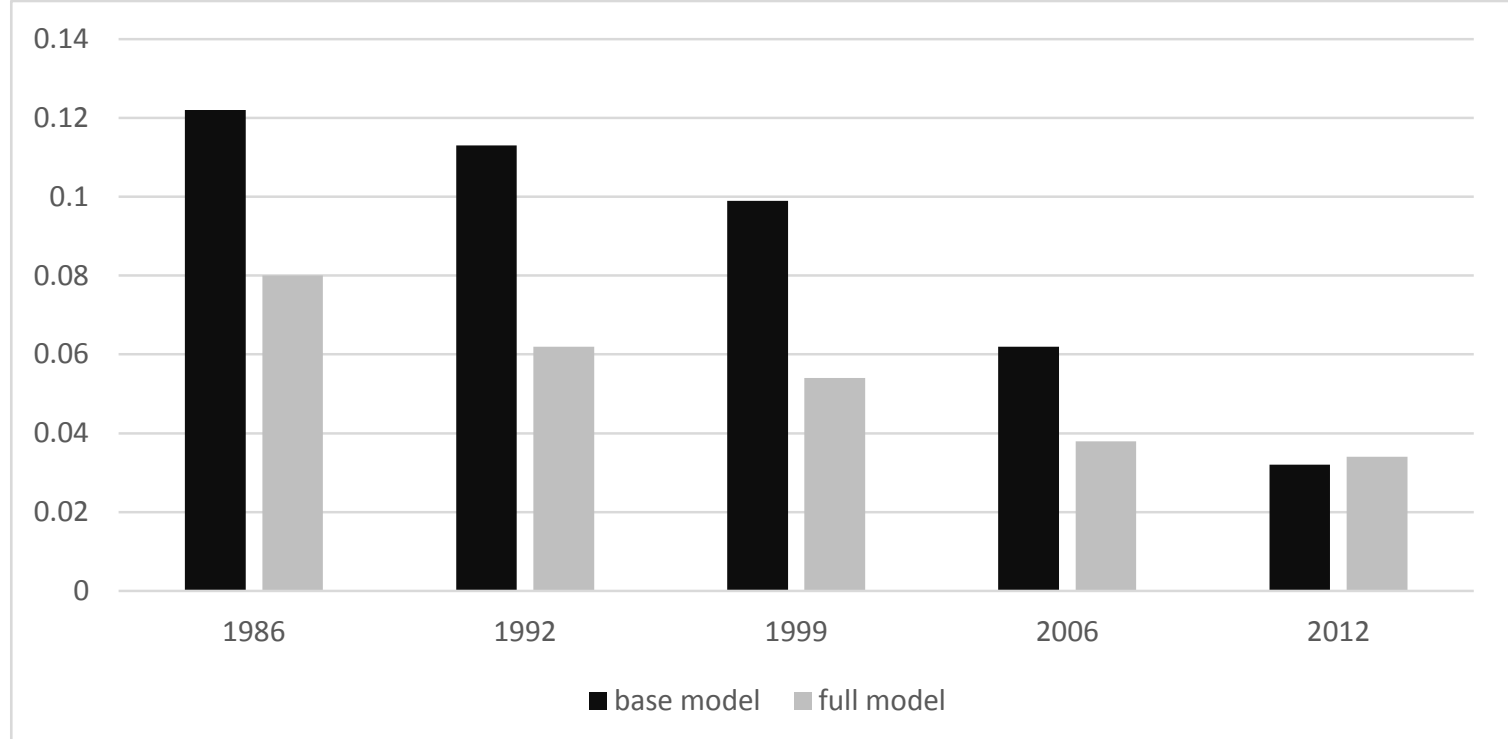

Data sources: IAB, BiBB, BAuA. Own calculations. See text for details.

Note: Base model: complexity as only regressor; full model according to equation (1). All displayed coefficients are significant on a $1 \%$-level.

The returns to complexity turn out to be slightly smaller when we estimate them in a pooled cross section with year-complexity interactions (Figure 4). In 1986, an increase of complexity by one standard deviation was associated with a wage increase of $8 \%$. The wage increase became smaller in all following years and had more than halved in 2012 (3.7\%).

Figure 4. Returns to Work Complexity (1986 to 2012, pooled OLS Estimates)

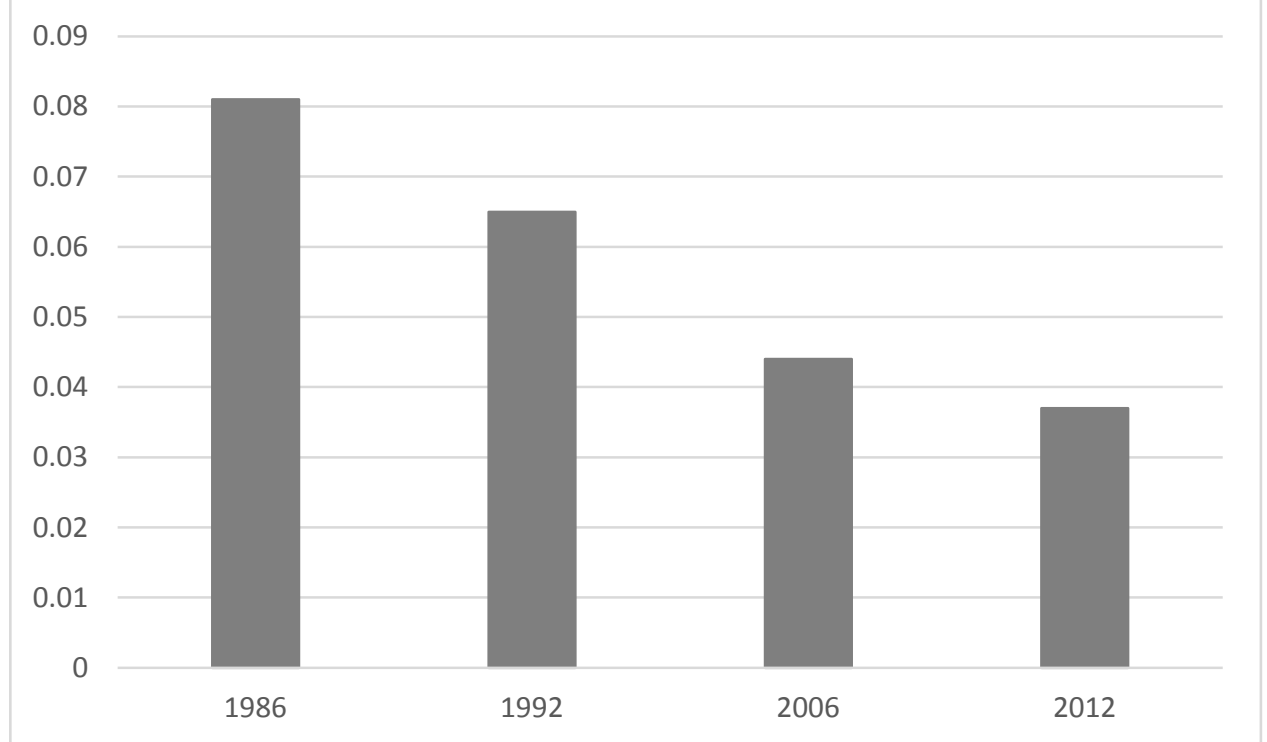

Data sources: IAB, BiBB, BAuA. Own calculations. See text for details.

Note: Based on equation (2) estimated in a pooled cross section. 1986 displays the estimated coefficient and standard error for complexity, $\beta_{1}$, while the other years show the sum of the complexity estimate and the corresponding year-complexity interaction, $\beta_{1}+\beta_{2}$. All displayed coefficients are significant on a $1 \%$-level. 
As expected, a low/higher school degree is associated with lower/higher wages. Turning to education specific returns to complexity, there is evidence that people with low education benefit more from complexity than people with medium education (Figure 5). Medium educated employees, in turn, benefitted more from complexity than highly-educated. In 2006 and 2012, the difference between the returns to complexity for medium and high educated is not statistically significant anymore. All in all, this analysis confirms (1) decreasing returns to complexity and (2) lower returns the more common to job complexity is.

Figure 5. Returns to Work Complexity by Education (1986 to 2012, pooled OLS Estimates)

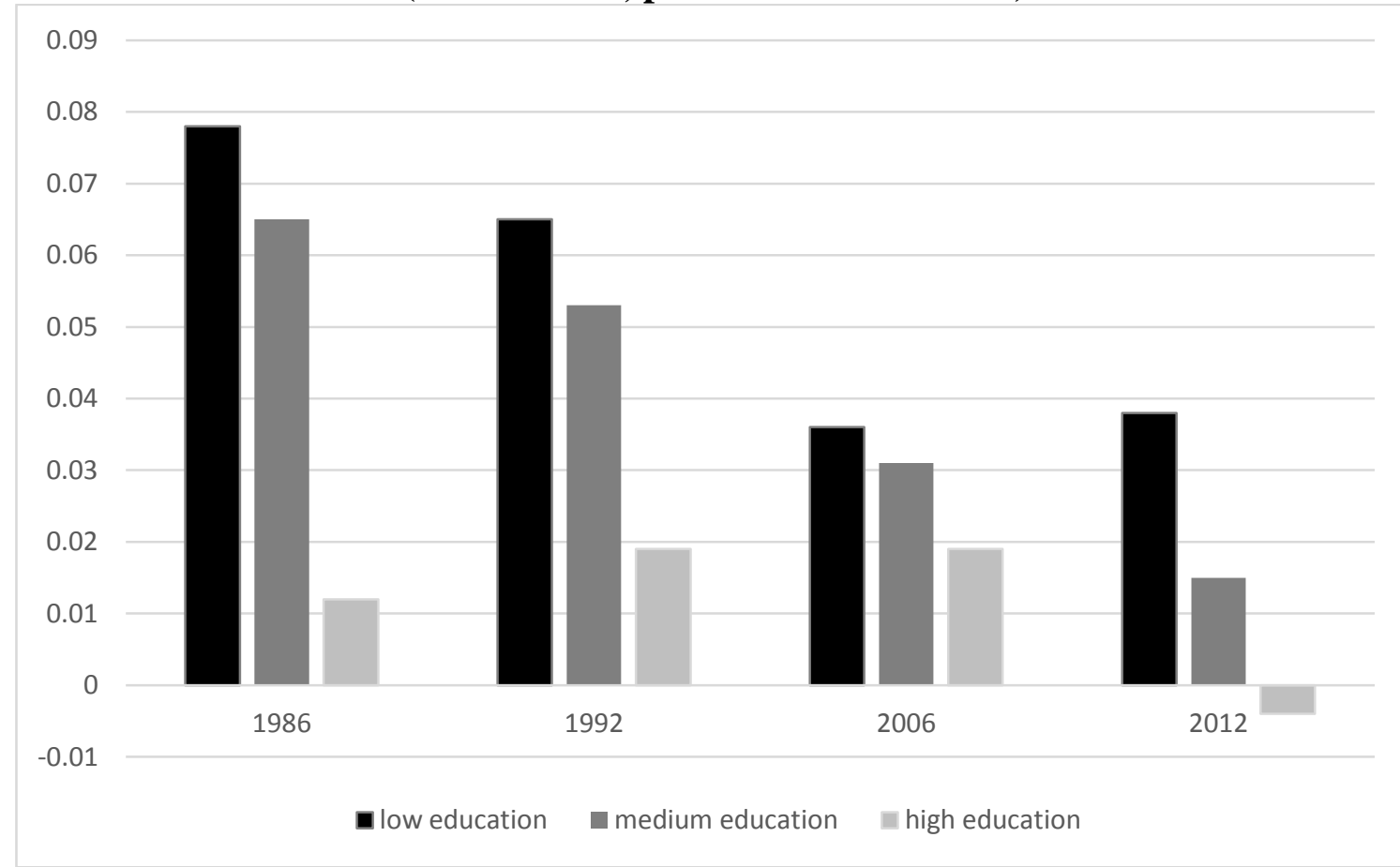

Data sources: IAB, BiBB, BAuA. Own calculations. See text for details.

Note: Based on equation (3). Low education is the estimated coefficient and standard error for complexity, $\beta_{1}$, medium and high education are the sum of the complexity estimate and the interaction term estimate. The interaction term with medium education is insignificant in all years except 2006, the interaction with high education is insignificant in 2006 and 2012. The remaining interactions are at least significant on a 10\%-level. All complexity estimates are significant at the $1 \%$-level.

Figure 6 shows the estimated returns to work complexity controlling for the absolute individual main task. Since 1986 , returns decreased from $4.4 \%$ to $1.2 \%$ in 2012 . It becomes clear that about half of the returns displayed in figures 3 and 4 are attributable to specific main individual tasks. Nevertheless, even when accounting for the main task category, complexity is associated with wage increases, and its returns reduce over time. Using the alternative main 
task definition yields similar results which can be found in column (10) in Table A.2 in the appendix.

Figure 6. Returns to Work Complexity with Main Task Controls (1986 to 2012, OLS Estimates)

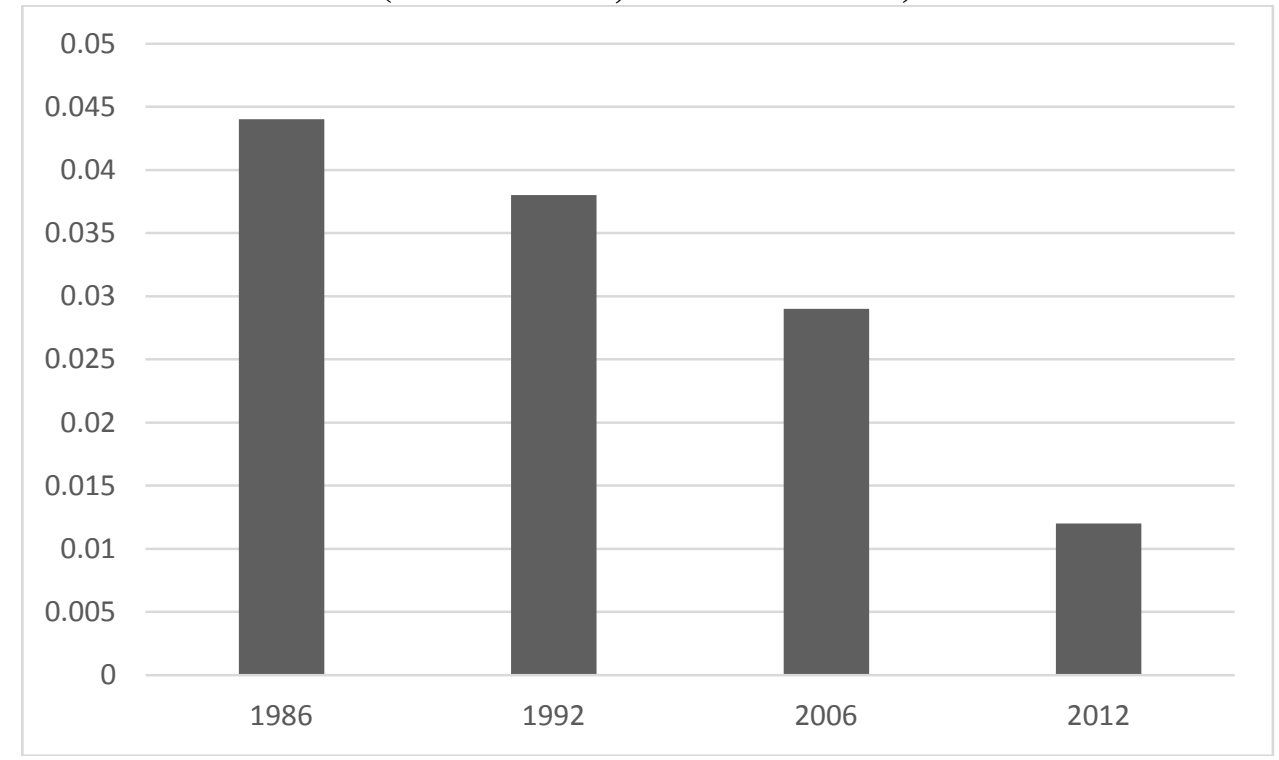

Data sources: IAB, BiBB, BAuA. Own calculations. See text for details.

Note: Based on equation (4) using the absolute individual main task definition. The estimates for 2012 is significant on the 5\%-level, all others are significant at the $1 \%$-level.

\section{Conclusion}

Work complexity is an important factor in contributing to the observed employment and wage developments. While in 1986, nearly $40 \%$ of people carried out tasks of a single category in their job only, from 1992 to 2012 complexity rose sharply. The share of people with one task category declined to about a third of the 1986-share, and the shares of people with three or more categories ascended steadily. In 2012, two out of three people carried out tasks of three or more categories. This development is also observable for different educational groups. In 1986, low-educated people performed 1.8 and high-educated 2.5 task categories. In addition to rising complexity over time, these initial differences reduced: Complexity is slightly below 3 for all education groups in 2012 . 
A likely reason for this observation may be that the advances in information and communications technologies require the combination of different tasks. As pointed out by Autor (2015), routine tasks cannot be isolated from non-routine tasks in which workers hold a comparative advantage (interpersonal interaction, flexibility, adaptability, and problemsolving). This interdependency could be a reason for the observed mitigation of the polarization phenomenon.

Rising work complexity tends to be associated with higher returns as indicated by the cross-section estimations but this relationship has weakened since 1986. The returns to complexity were substantially higher for low- and medium-educated compared to higheducated in 1986. Both, returns and the difference over education, decreased in 1992 and 2006. The explanatory power of work complexity rose up to $5.3 \%$ in the wage equation in 1992. Since then the association between complexity and wages has become weaker. It thus seems that the more it becomes "normal" to perform tasks of different categories (= the more people do it), the less complexity is important in determining the wage. A further implication of the results can be that wage polarization will reduce. As jobs become more complex, i.e. require a combination of different task categories, the initial differences in returns to nonroutine versus routine tasks will probably reduce and hence, wage polarization is likely to diminish, too. Differences across task categories decreased substantially and single task categories (relevant for polarization) are not characteristic for occupations anymore.

\section{References}

Acemoglu, D., and D. Autor (2011): "Skills, Tasks and Technologies: Implications for Employment and Earnings," in Card, D., and Ashenfelter, O. (Eds.): Handbook in Labor Economics, Vol. 4A, pp. 1043-1171, Amsterdam: North-Holland and Elsevier. 
Autor, D., F. Levy, and R. J. Murnane (2003): “The Skill Content of Recent Technological Change: An Empirical Exploration," Quarterly Journal of Economics, 118(4), 1279- 1334.

Autor, D. (2015): “Why Are There Still So Many Jobs? The History and Future of Workplace Automation.” Journal of Economic Perspectives, 29(3): 3-30.

Beaudry, P., D. A. Green, and B. M. Sand (2016): “The Great Reversal in the Demand for Skill and Cognitive Tasks.” Journal of Labor Economics, 34(S1), S199-S247.

Black, S. E., and A. Spitz-Oener (2010): "Explaining women's success: technological change and the skill content of women's work." The Review of Economics and Statistics 92.1: 187194.

Goos, M., A. Manning, and A. Salomons (2014): "Explaining Job Polarization: RoutineBiased Technological Change and Offshoring," American Economic Review, 104(8), 25092526.

Green, D. A., and B. M. Sand (2015): “Has the Canadian labour market polarized?" Canadian Journal of Economics, 48, 612-646.

Spitz-Oener, A. (2008): The Returns to Pencil Use Revisited, Industrial and Labor Relations Review, Vol. 61(4) 


\section{Appendix}

\section{Table A.1. Composition of Task Categories in Each Year}

\begin{tabular}{|c|c|c|c|c|c|}
\hline & non-routine manual & routine manual & routine cognitive & non-routine interactive & non-routine analytic \\
\hline 1986 & $\begin{array}{l}\text { repair, maintain; serve, } \\
\text { accomodate; nurse, treat }\end{array}$ & $\begin{array}{l}\text { construct, install; operate and } \\
\text { regulate machines; cultivate, } \\
\text { breed;extract raw materials; } \\
\text { produce, process; pack, load, drive; } \\
\text { clean; secure }\end{array}$ & $\begin{array}{l}\text { writing, calculations, book- } \\
\text { keeping }\end{array}$ & $\begin{array}{l}\text { publish, entertain; buy, sell, } \\
\text { advertise; instruct colleagues } \\
\text { educate, teach }\end{array}$ & $\begin{array}{l}\text { plan, construct; dispose, } \\
\text { direct; interpret rules; EDP, } \\
\text { program }\end{array}$ \\
\hline 1992 & serve; nurse, hairdressing & $\begin{array}{l}\text { building,construction, equipment; } \\
\text { operate machines; waste disposal; } \\
\text { pack, post; clean }\end{array}$ & buy/sell, purchase & buy/sell, advertise; hire staff & $\begin{array}{l}\text { construct, design; } \\
\text { coordinate, dispose }\end{array}$ \\
\hline 2006 & $\begin{array}{l}\text { repair, maintain; serve, } \\
\text { accomodate, cook; care, } \\
\text { nurse, treat }\end{array}$ & $\begin{array}{l}\text { operate machines, monitor; } \\
\text { produce }\end{array}$ & $\begin{array}{l}\text { measure, control, quality } \\
\text { control; purchase }\end{array}$ & $\begin{array}{l}\text { consult, inform; advertise, } \\
\text { marketing, PR; train, teach, } \\
\text { educate }\end{array}$ & $\begin{array}{l}\text { research, construct; } \\
\text { organize, plan working } \\
\text { porcesses }\end{array}$ \\
\hline 2012 & $\begin{array}{l}\text { repair, maintain; serve, } \\
\text { accomodate, cook; care, } \\
\text { nurse, treat }\end{array}$ & $\begin{array}{l}\text { operate machines, monitor; } \\
\text { produce; clean, recycle }\end{array}$ & $\begin{array}{l}\text { measure, control, quality } \\
\text { control }\end{array}$ & $\begin{array}{l}\text { consult, inform; advertise, } \\
\text { marketing, PR; train, teach, } \\
\text { educate }\end{array}$ & $\begin{array}{l}\text { research, construct; } \\
\text { organize, plan working } \\
\text { porcesses }\end{array}$ \\
\hline
\end{tabular}

Data sources: IAB, BiBB, BAuA. Own composition based on Spitz-Oener (2008). 
Table A.2. Returns to Complexity

\begin{tabular}{|c|c|c|c|c|c|c|c|c|c|c|c|}
\hline & & $\begin{array}{r}1 \\
\text { eq } \\
\text { base model }\end{array}$ & $\begin{array}{l}\quad 2 \\
\text { (1) } \\
\text { full model }\end{array}$ & $\begin{array}{c}3 \\
\text { eq. (2) } \\
\text { full model }\end{array}$ & $\begin{array}{c}4 \\
\text { eq. (3) } \\
\text { full model }\end{array}$ & $\begin{array}{c}5 \\
\text { eq. (3) } \\
\text { low } \\
\text { education }\end{array}$ & $\begin{array}{c}6 \\
\text { eq. (3) } \\
\text { high } \\
\text { education }\end{array}$ & $\begin{array}{c}7 \\
\text { eq. (3) } \\
\text { low } \\
\text { education }\end{array}$ & $\begin{array}{c}8 \\
\text { eq. (3) } \\
\text { high } \\
\text { education }\end{array}$ & $\begin{array}{c}9 \\
\text { eq. (4) } \\
\text { full model }\end{array}$ & $\begin{array}{c}10 \\
\text { eq. }(4)^{*} \\
\text { full model }\end{array}$ \\
\hline \multirow[t]{3}{*}{1986} & Coeff. & 0.122 & 0.080 & 0.081 & 0.065 & 0.013 & -0.053 & \multirow[t]{3}{*}{0.078} & \multirow[t]{3}{*}{0.012} & 0.037 & 0.044 \\
\hline & Std. Err. & 0.006 & 0.006 & 0.005 & 0.013 & 0.015 & 0.025 & & & 0.006 & 0.006 \\
\hline & adj. $R^{2}$ & 0.049 & 0.315 & 0.400 & 0.283 & 0.283 & 0.283 & & & 0.308 & 0.311 \\
\hline \multirow[t]{3}{*}{1992} & Coeff. & 0.113 & 0.062 & 0.065 & 0.053 & 0.012 & -0.034 & \multirow[t]{3}{*}{0.065} & \multirow[t]{3}{*}{0.019} & 0.029 & 0.038 \\
\hline & Std. Err. & 0.005 & 0.005 & 0.006 & 0.011 & 0.012 & 0.018 & & & 0.006 & 0.005 \\
\hline & $\operatorname{adj.} R^{2}$ & 0.053 & 0.398 & 0.400 & 0.357 & 0.357 & 0.357 & & & 0.375 & 0.383 \\
\hline \multirow[t]{3}{*}{2006} & Coeff. & 0.062 & 0.038 & 0.044 & 0.031 & 0.005 & -0.012 & \multirow[t]{3}{*}{0.036} & \multirow[t]{3}{*}{0.019} & 0.027 & 0.029 \\
\hline & Std. Err. & 0.006 & 0.005 & 0.006 & 0.008 & 0.011 & 0.012 & & & 0.005 & 0.005 \\
\hline & $\operatorname{adj} . R^{2}$ & 0.018 & 0.405 & 0.400 & 0.345 & 0.345 & 0.345 & & & 0.354 & 0.354 \\
\hline \multirow[t]{3}{*}{2012} & Coeff. & 0.032 & 0.034 & 0.037 & 0.015 & 0.023 & -0.019 & \multirow[t]{3}{*}{0.038} & \multirow[t]{3}{*}{-0.004} & 0.005 & 0.012 \\
\hline & Std. Err. & 0.006 & 0.005 & 0.006 & 0.008 & 0.011 & 0.014 & & & 0.005 & 0.005 \\
\hline & $\operatorname{adj} . R^{2}$ & 0.004 & 0.431 & 0.400 & 0.347 & 0.347 & 0.347 & & & 0.364 & 0.368 \\
\hline
\end{tabular}

Data sources: IAB, BiBB, BAuA. Own calculations. See text for details.

Note: If nothing else is stated, the displayed coefficients are significant on a $1 \%$-level. (1) and (2) show the estimated coefficients and standard errors for complexity in equation (1), $\beta_{1}$. Adj. R2 refers to the whole model, i.e. including all controls in (2). (3) is based on equation (2) and estimated in a pooled cross section, therefore, all Adj. R2 are the same. 1986 displays the estimated coefficient and standard error for complexity, $\beta_{1}$, while the other years show the sum of the complexity estimate and the corresponding year-complexity interaction, $\beta_{1}+\beta_{2}$. (4) - (6) are based on equation (3). (4) shows displays the estimated coefficient and standard error for complexity, $\beta_{1}$, (5) and (6) display the corresponding education-complexity interaction, $\beta_{3}$, and their standard errors. (7) and (8) display the sum of the complexity estimate and the corresponding education-complexity interaction, $\beta_{1}+\beta_{3}$, i.e. the numbers for figure 5. The interaction term with medium education is insignificant in all years except 2006, the interaction with high education is insignificant in 2006 and 2012 . The remaining interactions are at least significant on a 10\%-level. All complexity estimates are significant at the 1\%-level. (9) and (10) report the estimated coefficients and standard errors for complexity in equation (4), $\beta_{1}$, and the adj. R2 of the whole model. (9) uses the relative and (10) the absolute individual main task definition. In (9), the estimates for 2012 is significant on the 5\%-level, all others are significant at the $1 \%$-level. In (10), the estimated non-routine interactive interaction term is insignificant in 2006 and significant on a $5 \%$-level in 2012 . The complexity estimate is insignificant in 2012. 